\title{
Empirical Evaluation of a Mathematical Model of Ethnolinguistic Vitality: The Case of Vöro
}

\author{
Martin Ehala and Katrin Niglas \\ Tallinn University, Tallinn, Estonia
}

The paper presents the results of an empirical evaluation of a mathematical model of ethnolinguistic vitality. The model adds several new factors to the set used in previous models of ethnolinguistic vitality and operationalises it in a manner that would make it easier to compare the vitality of different groups. According to the model, the ethnolinguistic vitality (V) depends on the perceived cultural weight of one's own community $\left(M_{1}\right)$ in relation to the weight of a relevant other community $\left(M_{2}\right)$; perceived intergroup distance between the communities $(r)$ and the extent of utilitarianism $(U)$ in the community under investigation. The overall ethnolinguistic vitality can be expressed by a formula $V=U\left(M_{1}-M_{2}\right) / r$. In this paper, the model is applied for evaluating the vitality of the Vorro language, a minority language closely related to Estonian. The results are in concord with the results of previous studies about the language maintenance and shift in Võro.

doi: $10.2167 / j m m d 537.0$

Keywords: ethnolinguistic vitality, language maintenance, Võro language

\section{Introduction}

The goal of this paper is to test empirically a new model of ethnolinguistic vitality, proposed and elaborated in Ehala (2005, forthcoming). This model adds several new factors to the set used in previous models of ethnolinguistic vitality and tries to operationalise it in a manner that would make it easier to compare the vitality of different groups. The last property also enables the validity of the model to be tested empirically and thus opens it up to systematic refinement.

In this paper, the model is applied for evaluating the vitality of the Vorro language, a minority language closely related to Estonian. Although there are some studies addressing the maintenance of Võro, these works have been published in Estonian. Thus, one of the aims of this paper is to add the case of Võro to the pool of international studies of language maintenance and shift. On the other hand, the previous studies provide good comparison material to assess the validity of the model.

First, we will provide a short overview of the notion of ethnolinguistic vitality and the basic principles of the model. Next we present the essential facts about the Vorro language and its sociolinguistic situation. Then we outline the principles of the design of the study and its main results. In the discussion section we first compare our results with the outcomes of previous studies on 
Võro maintenance and shift to assess the validity of the model. The paper concludes with some suggestions for further elaboration of the model.

\section{The Notion of Ethnolinguistic Vitality}

The concept of ethnolinguistic vitality (henceforth V), introduced by Giles et al. (1977: 307), indicates the property 'which makes a group likely to behave as a distinctive collective within an intergroup setting'. Thus, the higher $\mathrm{V}$ is, the better the chances are for the maintenance of this group over time, and the weaker $\mathrm{V}$ is, the more likely it is to cease to exist through assimilation. To the extent a particular language is the main focus of a groups' identity, V is an important indicator of possible language shift or maintenance.

In first studies, it was assumed that the vitality manifests itself in the status, demographic situation and institutional support to the language (see Bourhis, 1979), but soon it was realised that the notion has a social psychological side which led to the introduction of the notion of subjective vitality (Bourhis et al., 1981). The notion of subjective vitality captures the fact that the group's perception of its vitality does not always follow from the objective factors of vitality (see for example Kraemer \& Olshtain, 1989; Pierson et al., 1987; Sachdev et al., 1990; Sachev \& Bourhis, 1993). In subsequent works the framework was further broadened, including also the social network dimension (Landry \& Allard, 1992, 1994). With variation, the vitality framework has been successfully applied also in recent studies (see Kindell \& Lewis, 2000; Klatter-Folmer \& Avermaet, 2001; Sayahi, 2005; Yağmur \& Kroon, 2003).

Although under different names, the set of factors that contribute to $\mathrm{V}$ have been studied within other theoretical frameworks, too. For example Fishman's (1991, 2001) reversing language shift framework presents eight levels of language endangerment, each of which could be characterised as a level of objective vitality of a language. The matrix offered by Edwards (1992) outlines 11 factors that partially overlap with the ones outlined by Giles et al. (1977). Edwards' (1992) system was later elaborated by Grenoble and Whaley (1998), and recently he (Edwards, 2006) has further elaborated it. Besides these, a number of other models of language maintenance and shift have been proposed, such as Smolicz (1981), Smolicz et al. (2001), Coulmas (1992) and Harris Russell (2001), to name a few.

However, the dynamics of language shift is so multifaceted that it forces Clyne (2003: 21) to conclude in his overview of the models of language shift that even though they are able to describe some aspects of language shift in an illuminating manner, 'no instrument powerful enough to assess language shift adequately on a large scale has yet been devised.'

\section{Principles of the V Model}

The vitality of a group depends on the behaviour of its members: the group is vital when the members associate strongly with the group and invest their time and energy in its functioning. The group ceases to exist when the members shift their loyalty to another collective. Thus, the vitality of the group is the consequence of cumulative individual actions. Although the actions of 
individual group members are influenced by reality, the perception of that reality is often and to a large extent created discursively.

This means that the objective economic, political and linguistic situation of the group as well as its demographic characteristics and factors of the institutional support get interpreted through public discourse, and the members of the group make their decisions based on this shared interpretation. In some cases, a group may perceive its standing stronger than it would appear to an outside observer; sometimes it may be weaker. Accordingly, V does not depend directly on objective factors. As Harris Russell (2001) notices, even two groups living in very similar external settings could have a radically different vitality: while one group is maintaining the other is going through a shift. It follows that the systematic study of objective vitality factors could never provide an accurate basis for assessing the $\mathrm{V}$.

Furthermore, as the objective social settings vary greatly across groups, there is little hope to compare the vitality of groups living in different conditions. Accounts that try to evaluate group vitality by assessing the objective determinants of the $\mathrm{V}$, will remain detailed descriptions of singular situations, at best. This means that it is impossible to design a theoretical model that would be formalised enough to make its outcomes comparable in a wide array of social settings using objective criteria. Despite this, such comparisons are necessary for both the refinement of the research instrument as well as making the notion of $\mathrm{V}$ something more than a metaphor.

Provided that individuals make the decisions leading to language maintenance or shift based on their subjective assessment of the vitality of their group, we claim that the combination of such subjective assessments is the direct indicator of the vitality of the particular group in a particular time. Thus, a more accurate expression of vitality could be obtained by measuring the socalled subjective ethnolinguistic vitality.

Interestingly, the subjectivity of $\mathrm{V}$ makes it possible to design a research instrument that could provide easily comparable results over very diverse settings: whatever the situation, the assessment of this situation by the participants could be expressed in a scale ranging from the worst to the best. No matter what the cause of these value assignments would be, its impact on the subjects is the same: the worse the situation is, the more likely it is that the subjects will be prone to actions leading to abandonment of this particular group membership and vice versa.

Studies of language attitudes (Baker, 1992; Ehala \& Niglas, 2006) have shown that attitudes towards a low status language are formed in a competitive situation with the dominant language. Thus, another important assumption of the model is that the vitality of the group is not an absolute measure, but the result of the comparison of the ingroup with prominent outgroups. This position is supported by the social identity theory (Tajfel \& Turner, 1979), according to which the group membership ought to provide its members a positive self-image. The self-image is created through comparison with outgroups: if the ingroup is felt to possess more power and higher status than the outgroups, positive self-image is achieved. If the outgroups are perceived to have higher status, self-image suffers. Thus, it could be argued that $\mathrm{V}$ is the function of this comparison: if the ingroup (and its language) is 
felt to be superior to the outgroups, the group has high vitality. If the ingroup is felt to be inferior, then some members would prefer another collective identity, which on the macro level manifests itself as low vitality leading to a possible language and identity shift.

This means that in order to be able to compare different groups' vitality, we have to compare the group members' perceptions of the relative status of their group to the status of outgroups. The status depends on various interdependent factors such as economic wealth, technological advancement, defence capabilities, liveliness of the culture, rich historic heritage, quality of life, etc. We call all these factors together 'the cultural mass'. Thus, the bigger the cultural mass, the higher the status is. Let us observe a group $G_{1}$ which lives in relative proximity to group $G_{2}$. To measure the vitality of $G_{1}$, one has to compare the cultural mass $M_{1}$ of the first group to the cultural mass of the other group, as they both are perceived by the members of $G_{1}$. This could be expressed by the simple formula in (1):

$$
V=M_{1}-M_{2}
$$

At a value of $V \geq 0$, the group $G_{1}$ has high vitality and it is stable (not assimilating). If $V<0$, the group has low vitality and is prone to assimilation, which increases more when the negative value of $V$ increases.

Of course, the vitality of the group does not depend only on the status of the group in comparison with outgroups. As Clyne (2003) notices in several occasions, the cultural differences between the groups also play important role. Assimilation of the low status group is more likely if it is culturally close to the high status outgroup; if the groups are very different, assimilation is less likely to occur or is slower. Thus the perceived intergroup distance $(r)$ between $G_{1}$ and $G_{2}$ reduces the assimilative drive that the status differences have on the members of the weaker group (see (2)). The larger the value of $r$ is, the more the impact of the status differences between $G_{1}$ and $G_{2}$ is reduced and the closer the value of $V$ gets to 0 (remember that in the case of $V \geq 0$, the group is stable):

$$
V=\left(M_{1}-M_{2}\right) / r
$$

The intergroup distance is certainly not the only factor that influences the possible assimilative behaviour of the members of the low status group. Some researchers have pointed out that membership in religious parochial schools favours maintenance (Kloss, 1966), and some (Scollon \& Scollon, 1995) have argued that utilitarian attitudes toward life and culture favour shift. In principle, each culture functions as an interplay of innovation and tradition. Some cultures are more utilitarian and innovative than others. Thus, low status groups with a predominantly utilitarian value system are more likely to assimilate than groups with a predominantly conservative value system. Let this factor be expressed by the index of utilitarianism $(U)$, which can vary between 0 and 2. The formula for calculating $V$ takes the following shape:

$$
V=U\left(M_{1}-M_{2}\right) / r
$$

If $U=0$, the whole equation gets reduced to zero $(V=0)$, meaning that the particular group is stable. It indeed is, if it is so conservative that it gives no value to utilitarian motives: members of this group value their way of living so 
much that even large differences in $M$ do not motivate them to assimilate to the outgroup. If $U=1$, the utilitarian and conservative values are balanced within the community and this factor does not influence the value of $V$. When the value of $U$ is larger than 1 (up to the maximum 2), the impact of the status differences are increased. This leads to the larger negative value of $V$, indicating low vitality.

This model is best suited for a situation where there are two competing groups. In reality, most interethnic settings involve more than just two groups. To measure $\mathrm{V}$ in these settings, the calculation must be computed for all significant outgroups $\left(\mathrm{G}_{1}-\mathrm{G}_{2}, \mathrm{G}_{1}-\mathrm{G}_{3}, \mathrm{G}_{1}-\mathrm{G}_{4}\right.$ etc. $)$. In the present study, the vitality of Vorro is calculated only in comparison to Estonian, as this is by far the most prominent outgroup for Võro speakers.

\section{Vöro Language}

Võro [v $\gamma \mathrm{ro}$ ] is traditionally considered one of the Southern dialects of Estonian, belonging to the Finnic branch of Uralic languages. However, for speakers of standard Estonian, Võro is unintelligible without sufficient education, because there are differences in all levels of grammar as well in phonology and lexicon. This fact and a wish to boost the prestige of Vorru have lead Vorro maintenance activists to promote the view that Võru is a separate Finnic language. This development has found some support (as well as opponents) both in the linguistic circles and amongst Estonian politicians.

The traditional Võru linguistic area is around 4.4 thousand square kilometres and the total population is around 70,000 people. The largest towns in the area are Vorru (14,500 inhabitants), Põlva (6400 inhabitants) and Antsla (2000 inhabitants). Thus, $32 \%$ of the population lives in towns, the rest in rural areas. The density of the population is 15.5 persons $/ \mathrm{km}^{2}$. Based on a recent survey (Pajusalu et al., 2000), around 30,000 people in the Võro area speak Võro regularly. The rest of the population (around 40,000 people) consists of those who have shifted to standard Estonian or have moved to the area from other parts of Estonia. There are also native Russians living in the area. As a point of comparison, the number of native speakers of Estonian in Estonia is around 900,000 , out of a total population of 1,300,000 people.

The first few books in Vorro dialect appeared at the end of the 19th century, but the literary standard was developed only in the 1990s. At present there are around 300 books published in Võro. There is one Võro language newspaper Uma Leht ('Our own newspaper') that appears fortnightly, and a regular fortnightly radio news broadcast. Cultural events (literature, theatre, folk music) in Võro are plentiful and vibrant. In the 2004 Eurovision Song Contest, Estonia was represented by a song in the Vorro language. This is perhaps the widest international publicity that the Võro language and culture have ever reached. Võro is not used as a language of instruction in schools or in kindergartens, but it is taught as a subject in 26 schools, which is around $75 \%$ of the schools in the area.

The Võro maintenance movement started in the late 1980s. In mid the 1990s, the activists achieved a considerable show of support from the Estonian state: in 1995, a state-funded research institution, the Võru Institute, was 
established. The goal of the institute is to advance the field of Võro studies and to promote the Võro language and culture. In addition to this, a state funded programme, 'South-Estonian language and culture 2000-2004', was established. The programme was renewed in 2005 for another four years.

Despite this financial support, the Võro movement has not achieved its goal of gaining legal status for Võro as a regional heritage language in Estonia. Such status would allegedly raise the prestige of the language as well as make it eligible for funding from the minority language support system of the European Union. The main reason for the resistance for giving Võro a legal status is the costs that this would induce for bilingual governmental services in the area. The main argument for rejecting the legal claim is that Vorro is not a separate language, but a dialect; and if legal status is given to Võro, it would provide a precedent for other dialects.

\section{The Study}

The main goal of the empirical study was to test the vitality model (V model) outlined above. The linguistic situation in the Vorro area was considered particularly suitable for this, as the community is relatively small, which makes it easier to manage the data collection. Also, the linguistic situation in Võro has been sufficiently documented, which enabled a meaningful comparison of research results.

The main methodological task was the operationalisation of the $\mathrm{V}$ model. Basically, the $\mathrm{V}$ model measures the attitudes towards two particular ethnolinguistic groups and their languages and cultures. Carrett et al. (2003) give a good overview of different approaches that have been used for this: direct methods involve questionnaires and interviews; the most common indirect method is the matched-guise test (Lambert et al., 1960).

One of the assumptions of the V model is that language shift is a cumulative consequence of the actions of individual language users, based on their assessment of the language situation in their environment. To be able to attain a synopsis of the attitudes of an entire group, a statistical quantitative study is preferred. Further, as the V model is a mathematical one, it needs data that can be easily expressed in numeric format. One of the best ways to meet these conditions is to use the survey method in a multiple choice questionnaire format with standardised Likert scales for answers. This is the approach that was taken also in the first studies subjective ethnolinguistic vitality such as Bourhis et al. (1981).

The components of the model were operationalised in the following manner: $M_{1}$ and $M_{2}$ were measured by 26 questions modified from the Subjective Vitality Questionnaires (Bourhis et al., 1981; Landry et al., 1996; see Table 1). Intergroup distance $r$ was measured by 22 questions. Five questions (see Table 3) were modified from the study of cultural distance by Babiker et al. (1980). In addition to this, a good indicator for intergroup distance is one's individual network of linguistic contacts (Landry et al., 1996). The remaining 17 questions (10 of them presented in Table 2) measuring $r$ were adopted from this study. For measuring $U, 12$ questions were adopted from the Portrait Values Questionnaire (PVQ, Schwartz, 2003) used in the European Social 
Table 1 The perceived cultural mass $M$ for Võro and Estonian

\begin{tabular}{|c|c|c|c|}
\hline Question: & $\begin{array}{c}M_{1} \\
\text { (Võro) }\end{array}$ & $\begin{array}{c}M_{2} \\
\text { (Estonian) }\end{array}$ & $M_{1}-\mathrm{M}_{2}$ \\
\hline $\begin{array}{l}\text { How much is ... language used in education } \\
\text { (nurseries, schools, universities)? }\end{array}$ & 2.6 & 6.1 & -3.6 \\
\hline $\begin{array}{l}\text { How much is ... language used in media } \\
\text { (newspapers, radio, TV and internet)? }\end{array}$ & 2.9 & 6.0 & -3.1 \\
\hline $\begin{array}{l}\text { How much is ... language appreciated in the } \\
\text { society? }\end{array}$ & 3.4 & 5.6 & -2.2 \\
\hline $\begin{array}{l}\text { How many wealthy employers and businessmen } \\
\text { are there among the ... people? }\end{array}$ & 3.3 & 5.3 & -1.9 \\
\hline $\begin{array}{l}\text { How strong will the ... language and culture be in } \\
20 \text { to } 30 \text { years in comparison with the present? }\end{array}$ & 2.6 & 4.6 & -1.9 \\
\hline $\begin{array}{l}\text { How would you estimate the population of ... } \\
\text { people? }\end{array}$ & 2.9 & 4.6 & -1.8 \\
\hline $\begin{array}{l}\text { How much is ... language appreciated } \\
\text { internationally? }\end{array}$ & 2.7 & 4.3 & -1.6 \\
\hline $\begin{array}{l}\text { How many eminent talents (writers, actors, artists, } \\
\text { singers, scientists, journalists) are there among } \\
\text { the ... people? }\end{array}$ & 3.8 & 5.3 & -1.5 \\
\hline $\begin{array}{l}\text { How much is ... culture and tradition appreciated } \\
\text { in the society? }\end{array}$ & 3.7 & 5.1 & -1.3 \\
\hline How affluent are the ... people? & 3.7 & 5.0 & -1.3 \\
\hline $\begin{array}{l}\text { How active are the } \ldots \text { people concerning matters in } \\
\text { their society? }\end{array}$ & 4.0 & 5.3 & -1.3 \\
\hline Is the social position of the $\ldots$ people fair? & 4.0 & 4.9 & -0.9 \\
\hline $\begin{array}{l}\text { How proud are the ... people about their cultural } \\
\text { heritage? }\end{array}$ & 5.2 & 5.5 & -0.3 \\
\hline Mean of the means & 3.4 & 5.2 & -1.8 \\
\hline
\end{tabular}

*The differences between $\mathrm{M}_{1}$ and $\mathrm{M}_{2}$ are significant at the 0.01 level.

Survey to measure value orientations across nations. PVQ is based on a well validated theory of universal human values (Schwartz, 1992). The questions adopted for measuring $U$ belong to Conservation and Openness to Change dimensions of this theory (see Table 4). In total, the questionnaire consisted of 60 questions. The detailed argumentation behind the design of the questionnaire and the choice of particular questions is presented in Ehala (forthcoming) and will not be discussed here further.

For the Võro study, the questionnaire was translated into standard Estonian and modified for the Võro situation: G1 was named võrokesed ('the Võro people') and G2 other Estonians. To use the label other Estonians for the 
Table 2 Network of personal linguistic contacts

\begin{tabular}{|l|c|}
\hline Questions: & Mean \\
\hline Which language are you using with your family members? & 1.9 \\
\hline $\begin{array}{l}\text { In which language are the cultural events (concerts, theatre, festivals) } \\
\text { that you attend? }\end{array}$ & 1.7 \\
\hline Which language are you using with your friends? & 1.6 \\
\hline $\begin{array}{l}\text { Which language are you using outside school (doing sports, hobbies, } \\
\text { travelling)? }\end{array}$ & 1.5 \\
\hline Which language are you using with your classmates? & 1.5 \\
\hline In which language are the radio broadcasts that you listen to? & 1.5 \\
\hline In which language are the newspapers that you read? & 1.4 \\
\hline Which language are you using in shops and services? & 1.4 \\
\hline Which language are you using with your teachers? & 1.4 \\
\hline In which language are the books that you read? & 1.3 \\
\hline
\end{tabular}

prominent outgroup was decided in consultation with native Võro people who claimed that vorrokesed do not oppose themselves to Estonians, but regard themselves as a subcategory. The questionnaire was then back translated to English by an independent translator to check the adequacy of the initial translation.

In addition to the main questions, the questionnaire included six questions pertaining the sex of the respondent, type of the curriculum in their school (normal, extended English tuition), area of settlement (town, settlement, rural), size of the school (comprehensive, gymnasium), their parents' income (high, average, low) and educational level (basic school, secondary, university).

As the previous studies (see Bot \& Stoessel, 2002; Valk, 1998) have indicated the special importance of the language attitudes of teenagers to language maintenance in the long run, this age group was chosen as the target of the study. The vitality questionnaire was administered for 9th graders in more than $90 \%$ of the Vorro linguistic area schools (34). While the majority of schools had only one 9th grade, some larger schools had two or more. In these schools only one class completed the questionnaire. The data collection was conducted by the teachers in September 2005. All teachers who participated agreed beforehand and received written instructions to ensure the objectivity and anonymity of the process. Altogether, the questionnaire was completed by 748 students (the mean age of the respondents was 15.16 years). As some schools did not participate and from larger schools only one class participated, the sample does not include the whole population of 14-16-year-old Võro students nor are the subregions represented exactly as in the population. However, as the main aim of the study was to test the vitality model and not to draw strict conclusions about the ethnolinguistic vitality of the Võro population, it was considered more important to ensure the reasonable size of all 
Table 3 Cultural distinctiveness of Võro people

\begin{tabular}{|l|c|}
\hline Questions: & Mean \\
\hline $\begin{array}{l}\text { How different is the character of the Võro people and compared with other } \\
\text { Estonians? }\end{array}$ & 4.1 \\
\hline Do the Võro people differ from other Estonians in their religious customs? & 3.9 \\
\hline Is the common Võro meal any different from the common Estonian meal? & 3.3 \\
\hline Is it possible to recognise a Võro person on the street by his looks? & 3.2 \\
\hline Are the Võro people disparaged or ridiculed in society? & 3.1 \\
\hline
\end{tabular}

subgroups for which the differences in vitality were expected on the basis of previous research.

\section{Results}

First, we will present the results of the questionnaire by all independent factors of the models $M, r$ and $U$, then differences in V. Further, the statistically significant differences in independent factors between sociodemographic groups will be outlined.

Table 1 presents the mean scores for questions pertaining to the cultural masses of Vorro $\left(M_{1}\right)$ and other Estonians $\left(M_{2}\right)$. The respondents were asked to indicate their opinion on a seven-point Likert scale. The end points were marked with verbal meanings (1, not at all; 7 , very much) as appropriate, and the rest of the scale was numeric. The indexes for $M_{1}$ and $M_{2}$ were calculated as the mean values of the 13 initial variables respectively. To explore if it is justified to combine these items in such a manner, the exploratory factor analysis and Cronbach's alpha were used. The results of factor analysis showed that initial variables meant to indicate our components $M_{1}$ and $M_{2}$ of the $\mathrm{V}$ model punched up to form respective factors. These results were also supported by Cronbach's alpha values, which for $M_{1}$ was 0.870 and for $M_{2}$ was 0.856 , while all the initial variables helped to increase the value of alpha.

As Table 1 shows, the cultural mass of Võro scored mostly below the middle point of the scale (4), while the mass of Estonian was valuated above the middle point of the scale for all questions. The largest numerical discrepancy is the mass difference in the functional domain of language, and the perception of the status of the languages reflects this closely. The smallest numerical discrepancy is the difference in cultural spheres. It is interesting that while the scores from the top to the bottom increase considerably for Vorro, they show a slight decline for Estonian. As a result, the perceived mass difference is more than 10 times higher on the top lines than on the bottom. A short summary of the Võro cultural mass would be that, while Võro people are proud and active in the cultural field, their language is neither utilised nor appreciated in the wider society.

The questions pertaining to the intergroup distance $r$ could be divided into two categories: one measures the distance between the groups by the structure 
of the individual network of linguistic contacts (Landry et al., 1996) and the other measures differences in culture and habits.

Table 2 presents the answers to the questions concerning the network of personal linguistic contacts. Respondents had a choice to indicate their contacts in Võro versus Estonian in seven-point Likert scales: only in Võro (7), mainly in Võro (6), more in Võro than in Estonian (5), equally in Võro and Estonian (4), more in Estonian (3), mainly in Estonian (2) and only in Estonian (1). Table 2 presents the means of the responses.

As Table 2 shows, the network of linguistic contacts is predominantly Estonian. Võru contacts occur somewhat at home, but also in cultural events (this seems to indicate that Vorro functions as a ritual language, not in everyday communication).

Five questions related to the cultural distinctiveness of Võro in comparison to Estonian (1, not distinct at all -7 , very distinct). The means to the questions are presented in Table 3.

The composite value intergroup distance $r$ between Vorro and Estonian (the mean of means) is 2.16. This is a rather low value of $r$ which can range from 1 (virtually no distance and distinctiveness) to 7 (very large distance). The intergroup distance indicated by belongingness to one or the other linguistic network and by cultural distinctiveness is also reflected in subjects' responses to the questions of how much they consider themselves to belong to the Vorro people and how much to the Estonian people. Thirty percent indicated a dominant or balanced Võro identity, whereas $92 \%$ indicated dominant or balanced Estonian identity. This shows, indeed, a very close connectedness between the two groups.

Utilitarianism was measured by 12 statements from Schwartz' (2003) Portrait Values Questionnaire of human values. The answers were mapped on the six-point Likert scale as in the original (the lower the score the more the respondent feels that the person described in the statement resembles them). Table 4 presents the means for the questions.

As Table 4 shows, four out of six statements related to conservativeness have means higher than the midpoint of the scale (3.5) and all questions pertaining to openness to change have scores lower than the midpoint. This indicates that the respondents are rather open to change and not particularly conservative.

To transform the results of these questions to the format required for $U$, the scale was reversed for the six statements relating to openness to change. This lead to unified scale where higher values indicated higher utilitarianism (higher openness to change and lower conservativeness) and lower values lower utilitarianism. As the index of utilitarianism $(U)$ ranges from 0 to 2 , the original six-point scale was transformed accordingly, so that the value of 6 in the questionnaire corresponded to 2 in the $U$-scale; and 1 in the questionnaire to zero in $U$-scale. This enabled the calculation of the mean value for the group of questions expressing $U$. For the given age group $U=1.26$. This is quite a high result.

To calculate $V$, all the relevant values calculated for the whole group were inserted into formula (3). The calculation is presented in (4): 
Table 4 Conservativeness and openness to change

\begin{tabular}{|l|c|}
\hline Questionnaire items & Mean \\
\hline $\begin{array}{l}\text { He believes that people should do what they are told to do. He thinks that } \\
\text { people should follow rules even if nobody is there to see. }\end{array}$ & 4.2 \\
\hline He appreciates tradition. He is trying to follow religious or family customs. & 3.8 \\
\hline $\begin{array}{l}\text { He appreciates being modest and moderate. He does not wish to attract } \\
\text { attention to himself. }\end{array}$ & 3.7 \\
\hline $\begin{array}{l}\text { He appreciates good behaviour. He tries not to do things that other people } \\
\text { would regard as improper. }\end{array}$ & 3.6 \\
\hline $\begin{array}{l}\text { It is important for him to live in a safe environment. He avoids everything that } \\
\text { could jeopardise his safety. }\end{array}$ & 3.3 \\
\hline $\begin{array}{l}\text { It is important for him that government would guarantee his security from all } \\
\text { threats. He wants the state to be strong and to be able to protect its citizens. }\end{array}$ & 3.1 \\
\hline $\begin{array}{l}\text { He appreciates coming up with new ideas and creativity. He likes to do things } \\
\text { his own way. }\end{array}$ & 2.8 \\
\hline $\begin{array}{l}\text { He seeks every opportunity for having fun. He likes to do things that give } \\
\text { pleasure. }\end{array}$ & 2.3 \\
\hline $\begin{array}{l}\text { He likes surprises and he always seeks new activities. He thinks that it is } \\
\text { necessary to get a lot of new experience in life. }\end{array}$ & 2.2 \\
\hline $\begin{array}{l}\text { He is looking for adventure and likes to take risks. He wants to have an } \\
\text { exciting life. }\end{array}$ & 2.2 \\
\hline $\begin{array}{l}\text { It is important for him to do things independently. He likes to be free and not } \\
\text { to depend on others. }\end{array}$ & 2.2 \\
\hline He appreciates a pleasant life. He likes pleasures. \\
\hline
\end{tabular}

$$
V=1.26 \times(3.4-5.2) / 2.16=-1.05
$$

Knowing that Võro vitality has a value of -1.05 amongst teenage population indicates that the group is not stable, but is assimilating. However, as there are no other studies for comparison, it is hard to tell at present what $V=-1.05$ actually means. It can be seen that using seven-point scales for measuring $M$, the maximum difference $M_{1}-M_{2}$ can be \pm 6 . As the maximum value of $U$ is 2 and the minimum value of $r$ is 1, the formula allows the value of $V$ to vary between 12 and -12 , but these extremes are very unlikely. Thus, it might be that the values of $V$ would cluster much closer to 0 . However, by looking at the $V$ values for different subgroups of this sample, we could attain the first comparative evidence for evaluating the model.

Geographically, five distinct areas emerged: (1) the core urban area, including the largest town Vorru and Antsla settlement and their surroundings; (2) the northern urban area including the second largest town Põlva and Räpina settlement, bordering with the speech area of Standard Estonian; (3) Kanepi, the core rural area, located between both urban areas; (4) the RõugeOrava peripheral rural area, bordering Russia in the east and Latvia in the 
Table 5 The vitality of Võro geographic regions

\begin{tabular}{|l|r|c|c|c|c|c|c||}
\hline & \multicolumn{1}{|c|}{$N$} & $V$ & $U$ & $r$ & $\boldsymbol{M}_{\mathbf{1}}$ & $\boldsymbol{M}_{\mathbf{2}}$ & $\boldsymbol{M}_{\mathbf{1}}-\mathbf{M}_{\mathbf{2}}$ \\
\hline Core rural area & 87 & -0.6 & 1.3 & 2.6 & 3.9 & 5.0 & -1.1 \\
\hline Rõuge-Orava rural area & 172 & -0.9 & 1.3 & 2.4 & 3.5 & 5.1 & -1.5 \\
\hline Core urban area & 233 & -1.2 & 1.3 & 2.2 & 3.4 & 5.2 & -1.8 \\
\hline Tsirguliina rural area & 25 & -1.3 & 1.2 & 2.2 & 3.0 & 5.1 & -2.1 \\
\hline Northern urban area & 229 & -1.4 & 1.3 & 2.1 & 3.3 & 5.4 & -2.1 \\
\hline
\end{tabular}

Table 6 Statistical significance of the difference between the means of $V$ for Vorro regions

\begin{tabular}{||l|c|c|c|c||}
\hline & $\begin{array}{c}\text { Core rural } \\
\text { area }\end{array}$ & $\begin{array}{c}\text { Rõuge-Orava } \\
\text { rural area }\end{array}$ & $\begin{array}{c}\text { Core urban } \\
\text { area }\end{array}$ & $\begin{array}{c}\text { Tsirguliina } \\
\text { rural area }\end{array}$ \\
\hline Northern urban area & 0.000 & 0.000 & 0.087 & 1.000 \\
\hline Tsirguliina rural area & 0.008 & 0.281 & 1.000 & \\
\hline Core urban area & 0.000 & 0.005 & & \\
\hline Rõuge-Orava rural area & 0.274 & & & \\
\hline
\end{tabular}

south; and (5) the Tsirguliina rural area, bordering with the speech area of Standard Estonian in the west. The results for these areas are presented in Table 5.

As Table 5 shows, Vorro vitality is the highest at the core rural area, and generally higher in rural areas, except in Tsirguliina, which borders the speech area of Standard Estonian. It is interesting to note that in the core rural area, the intergroup distance $r$ is perceived the largest, the cultural mass of the Vorro people $\left(M_{1}\right)$ highest and the cultural mass of other Estonians $\left(M_{2}\right)$ the lowest.

Not surprisingly, the lowest vitality was recorded in the northern urban area, where the intergroup distance is felt to be the smallest and the cultural mass of other Estonians highest. The reason for this is perhaps that this region has a high percentage of non-Võro population. The statistical significance of the means of $V$ between groups is presented in Table 6. Except Tsirguliina, the differences among the rest of the regions are statistically significant, most of them at the 0.05 level.

This indicates that urban versus rural setting is an important factor determining V: vitality is higher in rural areas than in urban ones. The other significant factor is gender: for males, $V=-0.9$, for females, $V=-1.3$. Combining the geographical and gender factors provides a clear pattern of variation in $\mathrm{V}$, presented in Table 7.

As seen in Table 7, urban females have the lowest vitality: they perceive little intergroup distance from standard Estonian, they value Vorro cultural mass the least and the mainstream Estonian cultural mass the most. For this group, the difference in $\mathrm{V}$ is statistically significant at the 0.05 level with all the 
Table 7 The vitality of sociodemographic groups in Võro area

\begin{tabular}{|l|r|c|c|c|c|c|c||}
\hline & \multicolumn{1}{|c|}{$N$} & $\boldsymbol{V}$ & $\boldsymbol{U}$ & $\boldsymbol{r}$ & $\boldsymbol{M}_{\mathbf{1}}$ & $\boldsymbol{M}_{\mathbf{2}}$ & $\boldsymbol{M}_{\mathbf{1}}-\mathbf{M}_{\mathbf{2}}$ \\
\hline Rural males & 166 & -0.9 & 1.3 & 2.4 & 3.5 & 5.0 & -1.5 \\
\hline Small town males & 95 & -0.9 & 1.3 & 2.5 & 3.6 & 5.0 & -1.4 \\
\hline Rural females & 149 & -1.1 & 1.2 & 2.2 & 3.4 & 5.1 & -1.8 \\
\hline Urban males & 90 & -1.1 & 1.2 & 2.2 & 3.5 & 5.2 & -1.8 \\
\hline Small town females & 94 & -1.3 & 1.3 & 2.2 & 3.5 & 5.5 & -2.0 \\
\hline Urban females & 121 & -1.5 & 1.3 & 2.0 & 3.2 & 5.4 & -2.2 \\
\hline
\end{tabular}

other groups except the small town females. The latter group is statistically significantly different at the 0.05 level with rural and small town males.

\section{Discussion}

To evaluate the validity of the model, the main question is whether the results, the values of $\mathrm{V}$, really express the ethnolinguistic vitality of the group and whether there is an internal consistency in the model. For the first purpose, the sample for this study was chosen so that there would be some external information available concerning the language maintenance situation in the field.

In 1998, a large-scale survey concerning the usage of Vorro was conducted in South Eastern Estonia including 600 respondents from the ages of 25 to 65 (see Pajusalu et al., 2000). Although the subjects of the present study were considerably younger, other sociodemographic variables could provide comparable data. As a matter of fact, the results obtained by our study concur closely to some of the earlier findings by Pajusalu et al. (2000):

(1) Võro is less used outside the borders of Võro County. Our study revealed that the vitality of Võro is lower in the Põlva-Räpina and Tsirguliina areas that lie outside the Võro County.

(2) Võro is used more often in rural areas. Our study indicated that Võro is more vital in the rural than in the urban areas.

(3) Males use Võro more than females, who tend to prefer standard language. Our study indicated that the males have higher Võro vitality than females.

Further, the internal validity and actual usefulness of the model could be evaluated by investigating whether the application of the model actually brings out patterns that would otherwise not be apparent in the raw data, or would not be as clearly visible. For that purpose, the correlations between the vitality index and four components of the model (utilitarianism, the perceived cultural masses of groups and intergroup distance) were calculated. According to the results in Table 8 the four components were only very moderately correlated to each other (all but one correlation coefficients were under 0.2; the 
Table 8 Correlations between the components of the formula

\begin{tabular}{|l|c|c|c|c|c|c||}
\hline$N=746$ & $V$ & $U$ & $r$ & $M_{1}$ & $M_{2}$ & $\boldsymbol{M}_{\mathbf{1}}-\mathbf{M}_{\mathbf{2}}$ \\
\hline$V$ & 1.00 & & & & & \\
\hline$U$ & -0.36 & 1.00 & & & & \\
\hline$r$ & 0.52 & -0.04 & 1.00 & & & \\
\hline$M_{1}$ & 0.64 & -0.15 & 0.32 & 1.00 & & \\
\hline$M_{2}$ & -0.56 & 0.07 & -0.17 & 0.13 & 1.00 & \\
\hline$M_{1}-M_{2}$ & 0.90 & -0.17 & 0.37 & 0.68 & -0.64 & 1.00 \\
\hline
\end{tabular}

correlation between $r$ and $M_{2}$ was 0.316 ) and only the index of utilitarianism had somewhat lower correlation with the vitality while the correlations between vitality index and other three components were very similar. On the other hand the difference between $M_{1}$ and $M_{2}$ as calculated within the formula has rather high correlation with the final vitality index but not with other components ( $U$ and $r$ ) of the formula. The former is obviously due to the fact that the index of utilitarianism did not work in our context and therefore the vitality index in our example is determined practically by the measures of intergroup distance and difference between perceived cultural masses. These facts support the results of an empirical analysis presented above, which shows that the proposed combination of components brings out new patterns in data compared to the analysis of the individual components.

To double-check if the natural grouping of the cases on the bases of the independent components of the model would produce the same vitality patterns as our formula, we used $k$-means cluster analysis. Based on this, the cluster model with four groups was chosen to be compared with vitality as calculated using the $\mathrm{V}$ model and with background variables for which there is some information concerning the vitality patterns from previous studies. As can be seen from Table 9, the clusters have clear differences in vitality, which suggests that our vitality index is in concordance with the internal logic of the data. On the other hand we can see that tendencies which could be expected, taking into account previous knowledge about the group, appear: the results show higher vitality for male than for female and people from urban areas have considerably lower vitality than people from rural areas.

Thus, the results of previous studies largely overlap with the vitality patterns of the Vorro people which emerged in the present study and were described in the sections above. Therefore, we can claim that the set of indicators we have chosen to construct the vitality model is reasonable. However, there could be some other aspects that influence the ethnolinguistic vitality. For example, Tajfel and Turner (1979) argue that if the low status of the ingroup is perceived to be legitimate, the members of the group are more likely to abandon their membership. If the situation is perceived to be illegitimate, the members could be more prone to fight collectively for improvement. Similarly, if a group membership is marked by features that 


\begin{tabular}{|c|c|c|c|c|}
\hline 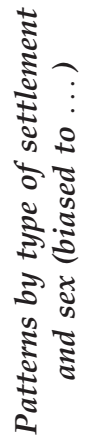 & 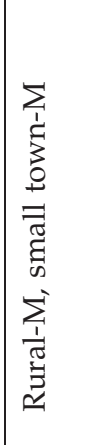 & 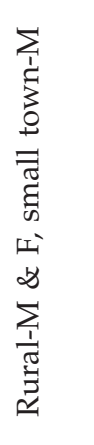 & 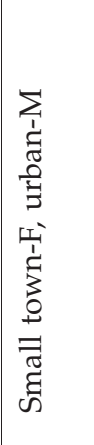 & 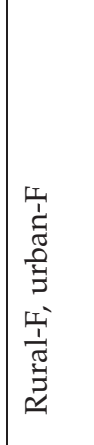 \\
\hline 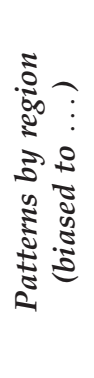 & 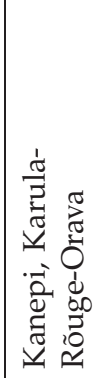 & 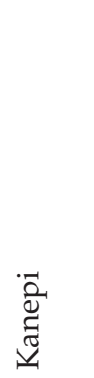 & 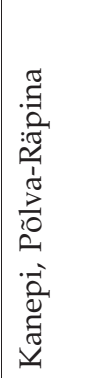 & 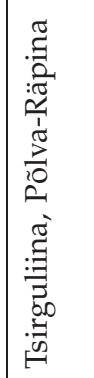 \\
\hline 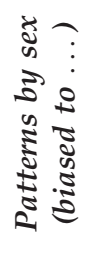 & $\frac{0}{\Sigma}$ & 离 & 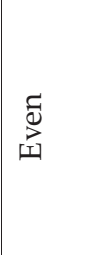 & 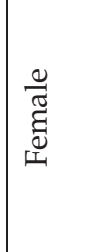 \\
\hline $\begin{array}{l}\text { ¿ } \\
\text { N } \\
\text { N }\end{array}$ & $\stackrel{\widehat{\sigma}}{\sim}$ & $\triangleright$ & $\stackrel{\rightleftharpoons}{\circ}$ & $\stackrel{\Re}{\widehat{N}}$ \\
\hline 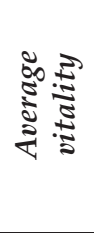 & $\begin{array}{l}n \\
0 \\
1\end{array}$ & 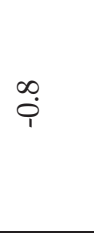 & $\stackrel{\circ}{\stackrel{+}{r}}$ & $\underset{T}{\stackrel{9}{T}}$ \\
\hline 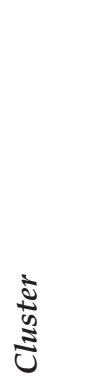 & 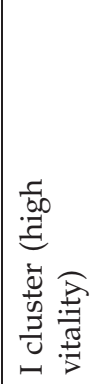 & 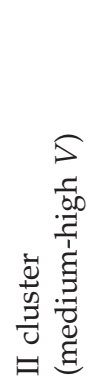 & 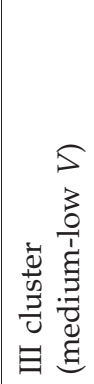 & 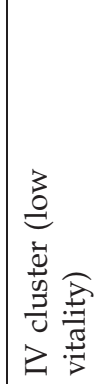 \\
\hline
\end{tabular}


are virtually impossible to change (distinct racial features, for example), assimilation is less likely. In considerably more neutral settings, these factors may not have a large impact on the vitality, but if these issues are prominently marked in the discourse, their effect to the vitality might be significant. Therefore, we suggest that there is a need for further research to study the possibilities of elaborating the $\mathrm{V}$ model.

The other aspect related to the application of the model, which needs further consideration and work, is the way the components of the V model ought to be measured and composed. It appeared that in our study the variables for utilitarianism $(U)$ did not correlate with each other considerably, which was also illustrated by the relatively low value of Cronbach $\alpha(\alpha=0.686$; the $\alpha$-values for other three components of the model were $\approx 0.85$ ). This led us to the situation where the variability of the $U$-value was considerably lower than the variability of the original variables, whereby the influence of the $U$ to the final $V$-value was very low.

This could be explained by the fact that the six value types under the two broad value dimensions: openness to change (stimulation, self-direction) and conservation (conformity, tradition, security) in Schwartz (2003) are conceptually very diverse, and might not therefore have been the best choice to express a single component $U$ in a meaningful manner. To raise the internal consistency of $U$, it would be desirable to formulate a new set of variables directly following the principles of the utilitarian discourse as outlined by Scollon and Scollon (1995).

\section{Conclusion}

This study is the first empirical testing of the model of ethnolinguistic vitality that aims to provide a standardised matrix for expressing the vitality of ethnolinguistic groups in a directly comparable manner. Although the results are encouraging, the model certainly needs improvement in its internal consistency as well as in its power to explain the interplay of factors that contribute to ethnolinguistic maintenance or assimilation. Also, it is too early to say whether the model would provide valid estimates of ethnolinguistic vitality in other very diverse social settings that could be found in other linguistic contact situations in the world. Yet we believe that this path of inquiry is worth pursuing, not least that such a model would be very useful for practical language maintenance practitioners as a diagnostic tool and also for deeper understanding of the processes underlying language maintenance and shift.

\section{Correspondence}

Any correspondence should be directed to Martin Ehala, Tallinn University, Narva Rd 25, Tallinn EE10120, Estonia (ehalam@gmail.com).

\section{References}

Babiker, I.E., Cox, J.L. and Miller, P. (1980) The measurement of cultural distance and its relationship to medical consultations, symptomatology, and examination performance of overseas students at Edinburgh University. Social Psychiatry 15, 109-116. 
Baker, C. (1992) Attitudes and Language. Clevedon: Multilingual Matters.

Bourhis, R.Y. (1979) Language in ethnic interaction: A social psychological approach. In H. Giles and B. Saint-Jacques (eds) Language and Ethnic Relations (pp. 117-142). Oxford: Pergamon.

Bourhis, R.Y., Giles, H. and Rosenthal, D. (1981) Notes on construction of a 'subjective vitality questionnaire' for ethnolinguistic groups. Journal of Multilingual and Multicultural Development 2 (2), 145-155.

Carrett, P., Coupland, N., and Williams, A. (2003) Investigating Language Attitudes. Social Meanings of Dialect, Ethnicity and Performance. Cardiff: University of Wales Press.

Clyne, M. (2003) Dynamics of Language Contact. English and Immigrant Languages. Cambridge: Cambridge University Press.

Coulmas, F. (1992) Die Wirtschaft mit der Sprache. Frankfurt: Suhrkamp.

de Bot, K. and Stoessel, S. (2002) Introduction: Language change and social networks. International Journal of the Sociology of Language 153, 1-7.

Edwards, J. (1992) Sociopolitical aspects of language maintenance and loss: Towards a typology of minority language situations. In W. Fase, K. Jaspaert and S. Kroon (eds) Maintenance and Loss of Minority Languages (pp. 37-54). Amsterdam: Benjamins.

Edwards, J. (2006) Players and power in minority-group settings. Journal of Multilingual and Multicultural Development 1, 4-21.

Ehala, M. (2005) The role of MTE in language maintenance and developing multiple identities. In S. Kiefer and K. Sallamaa (eds) European Identities in Mother Tongue Education: Texts from the EUDORA Intensive Programme MTE during the Summer School in Tolmin, Slovenia 2005 (pp. 36-50). Linz: Trauner Verlag.

Ehala, M. (forthcoming) An evaluation matrix for ethno-linguistic vitality. In S. Pertot, T. Priestly and C. Williams (eds) Rights, Promotion and Integration Issues for Minority Languages in Europe. Palgrave: MacMillan.

Ehala, M. and Niglas, K. (2006) Language attitudes of Estonian secondary school students. Journal of Language, Identity and Education 5 (3), $209-227$.

Fishman, J.A. (1991) Reversing Language Shift. Theoretical and Empirical Foundations of Assistance to Threatened Languages. Clevedon: Multilingual Matters.

Fishman, J.A. (ed.) (2001) Can Threatened Languages be Saved? Reversing Language Shift, Revisited: A 21st Century Perspective. Clevedon: Multilingual Matters.

Giles, H., Bourhis, R.Y. and Taylor, D.M. (1977) Towards a theory of language in ethnic group relations. In H. Giles (ed.) Language, Ethnicity and Intergroup Relations (pp. 307-348). London: Academic Press.

Grenoble, L.A. and Whaley, L.J. (1998) Toward a typology of language endangerment. In L.A. Grenoble and L.J. Whaley (eds) Endangered Languages: Language Loss and Community Response (pp. 22-54). Cambridge: Cambridge University Press.

Harris Russell, S.A. (2001) Towards predicting ethnolinguistic vitality: A sociocultural approach. In T. Ammerlaam, M. Hulsen, H. Strating and K. Yagmur (eds) Sociolinguistic and Psycholinguistic Perspectives on Maintenance and Loss of Minority Languages (pp. 139-152). Münster: Waxmann.

Kindell, G. and Lewis, P.M. (eds) (2000) Assessing Ethnolinguistic Vitality: Theory and Practice. Selected Papers from the Third International Language Assessment Conference. Dallas, TX: SIL International.

Klatter-Folmer, J. and van Avermaet, P. (eds) (2001) Theories on Maintenance and Loss of Minority Languages: Towards a More Integrated Explanatory Framework. Münster: Waxmann.

Kloss, H. (1966) German American language maintenance efforts. In J. Fishman, V.V.C. Nahirny, J.E. Hofman and R.G. Hayden (eds) Language Loyalty in the United States (pp. 206-252). The Hague: Monton.

Kraemer, R. and Olshtain, E. (1989) Perceived ethnolinguistic vitality and language attitudes: The Israeli setting. Journal of Multilingual and Multicultural Development 10, 197-212.

Lambert, W., Hodgson, R., Gardner, R. and Fillenbaum, S. (1960) Evaluational reactions to spoken languages. Journal of Abnormal and Social Psychology 60, 44-51. 
Landry, R. and Allard, R. (1992) Ethnolinguistic vitality and the bilingual development of minority and majority group students. In W. Fase, K. Jaspaert and S. Kroon (eds) Maintenance and Loss of Minority Languages (pp. 223-251). Amsterdam: Benjamins.

Landry, R. and Allard, R. (1994) Diglossia, ethnolinguistic vitality and language behavior. International Journal of the Sociology of Language 108, 15-42.

Landry, R., Allard, R. and Henry, J. (1996) French in South Louisiana: Towards language loss. Journal of Multilingual and Multicultural Development 17, 442-468.

Pajusalu, K., Koreinik, K. and Rahman, J. (2000) Lõunaeesti keele kasutusest KaguEestis. In K. Koreinik and J. Rahman (eds) A kiilt rahvas kynôlos ... Vorrokeste keelest, kommetest, identiteedist (pp. 13-37). Võru: Võro Instituut.

Pierson, H.D., Giles, H. and Young, L. (1987) Intergroup vitality perceptions during a period of political uncertainty: The case of Hong Kong. Journal of Multilingual and Multicultural Development 8, 451-460.

Sachdev, I. and Bourhis, R.Y. (1993) Ethnolinguistic vitality: Some motivational and cognitive considerations. In M. Hogg and D. Abrams (eds) Group Motivation: Social Psychological Perspectives (pp. 33-51). New York and London: Harvester/Wheatsheaf.

Sachdev, I., Bourhis, R.Y., D'Eye, J. and Phang, S. (1990) Cantonese-Chinese vitality in London. Journal of Asian and Pacific Rim Communication 1, 209-228.

Sayahi, L. (2005) Language and identity among speakers of Spanish in northern Morocco: Between ethnolinguistic vitality and acculturation. Journal of Sociolinguistics 9 (1), 95-107.

Schwartz, S.H. (1992) Universals in the content and structure of values: Theoretical advances and empirical tests in 20 countries. In M.P. Zanna (ed.) Advances in Experimental Social Psychology (Vol. 25, pp. 1-65). San Diego, CA: Academic Press.

Schwartz, S.H. (2003) A proposal for measuring value orientations across nations. In European Social Survey Questionnaire Development Report. http://66.102.1.104/ Scholar?hl = en\&lr = \&q = cache:v2_9jdf9wxuj:naticent02.uuhost.uk.uu.net / questionnare/chapter_07.doct. Accessed 22.09.2007.

Scollon, R. and Scollon, S. (1995) Intercultural Communication: A Discourse Approach. Oxford: Blackwell.

Smolicz, J.J. (1981) Core values and ethnic identity. Ethnic and Racial Studies 4, 75-90.

Smolicz, J.J, Secombe, M.J. and Hunter, D.M. (2001) Family collectivism and minority languages as core values of culture among ethnic groups in Australia. Journal of Multilingual and Multicultural Development 22, 152-172.

Tajfel, H. and Turner, J.C. (1979) An integrative theory of intergroup conflict. In W.G. Austin and S. Worchel (eds) The Social Psychology of Intergroup Relations (pp. 33-47). Monterey, CA: Brooks/Cole.

Valk, A. (1998) Mitte-eesti noorte psühholoogiline kohanemine mitmerahvuselises klassis: Enesehinnang ja etniline identiteet. In M. Lauristin, S. Vare, T. Pedastsaar and M. Pavelson (eds) Mitmekultuuriline Eesti: Väljakutse Haridusele (pp. 401-426). Tartu: Tartu Ülikool.

Yağmur, K. and Kroon, S. (2003) Ethnolinguistic vitality perceptions and language revitalisation in Bashkortostan. Journal of Multilingual and Multicultural Development 4, 319-336. 